\title{
The effect of different artificial grasslands on the soil organic carbon content in a degraded land
}

\author{
Zhuo Pang ${ }^{1}$, a, Tiejun Sun ${ }^{1}$, Juying $\mathrm{Wu}^{1}$, Haiming Kan ${ }^{1}$, Wei Hu${ }^{1}$, Xiaona $\mathrm{Li}^{1}$ \\ and Junyi Jian \\ ${ }^{1}$ No. 9, Middle of Shuguang Garden Road, Haidian District, Beijing, China \\ apangzh-84@163.com
}

Keywords: Degraded land, Ecological restoration, Artificial grassland, Soil total organic carbon, Components of soil organic carbon

Abstract. To evaluate the improving effects of artificial grassland restoration measures on soil organic carbon (SOC), soil with different depths, $0-5 \mathrm{~cm}$ and $5-10 \mathrm{~cm}$, was sampled and three components of SOC, i.e., total organic carbon (TOC) content, water soluble organic carbon (WSOC) content, and hot-water extractable organic carbon (HWEOC) content were measured in artificial grasslands of smooth brome (Bromus inermis) and alfalfa (Medicago sativa) synchronously. Based on the comparison of effects on soil organic carbon pool between these two kinds of artificial grassland, the preliminary conclusions are obtained as follows. Firstly, both artificial grasslands of smooth brome and alfalfa can considerably increase soil TOC for topsoil $(0-10 \mathrm{~cm})$ on annual time scale; meanwhile, the monthly fluctuation of TOC for topsoil was violent throughout the year, which may be driven by both phenology of plant species and variation of elemental factors. Moreover, on one-year scale, the TOC of topsoil in alfalfa grassland was higher than that in smooth brome grassland, while WSOC at 0-5 cm soil depth were significantly higher than that at $5-10 \mathrm{~cm}$ soil depth, and HWEOC exhibited no difference between the two soil depths. Finally, for the improving effect on all components of SOC, alfalfa grassland performed slightly better than smooth brome grassland, but the difference was not significant, and long-term monitoring is needed.

\section{Introduction}

Land use changes lead to changes in soil organic carbon (SOC) content, and soil organic carbon is pivotal to water holding capacity, retention of applied nutrients, biological and enzymatic activities of soil. Therefore improvement of SOC in soils is critical to degraded land subject to ecological restoration [1, 2]. However, compared with the large background value, the subtle improvement in SOC induced by ecological restoration measurements is difficult to detect [3,4]. As a result, SOC related indicators that are sensitive to short-term ecological restoration measurements are desirable. Except for total organic carbon (TOC) content, water soluble organic carbon (WSOC) content, and hot-water extractable organic carbon (HWEOC) content determining the labile pool of soil carbon are useful indicators for monitoring changes in SOC caused by land use changes or management practices $[5,6,7]$.

In this study, we analyze 44 soil samples, collected in two kinds of artificial grasslands, an ecological restoration measurement for repairing degraded land. We determined the contents of TOC, WSOC and HWEOC of soils at different depth in various months within one year in the laboratory. Our first objective was to demonstrate monthly variation of TOC for soil at different depths in artificial grasslands. We also compared components of SOC between two kinds of grassland to evaluate the effect of artificial grassland on improvement of SOC.

\section{Material and method}

The study was conducted at the experimental zone of the Beijing Seedling Nursery for the Sandstorm Source Control Project (SN-SSCP, 40 27'53"N, 115 $50^{\circ} 23^{\prime \prime} \mathrm{E}$ ) in Yanqing County Beijing Municipality of China (Fig. 1). The SN-SSCP, with an elevation of $501 \mathrm{~m}$, is located $73 \mathrm{~km}$ northwest 
of Beijing Downtown and on the northwest coast of Guanting reservoir, which is one of the source of drinking water of Beijing City (Fig. 1). The temperate continental monsoon climate has a mean annual temperature of $\approx 8.4{ }^{\circ} \mathrm{C}$ and precipitation of $466 \mathrm{~mm}$.

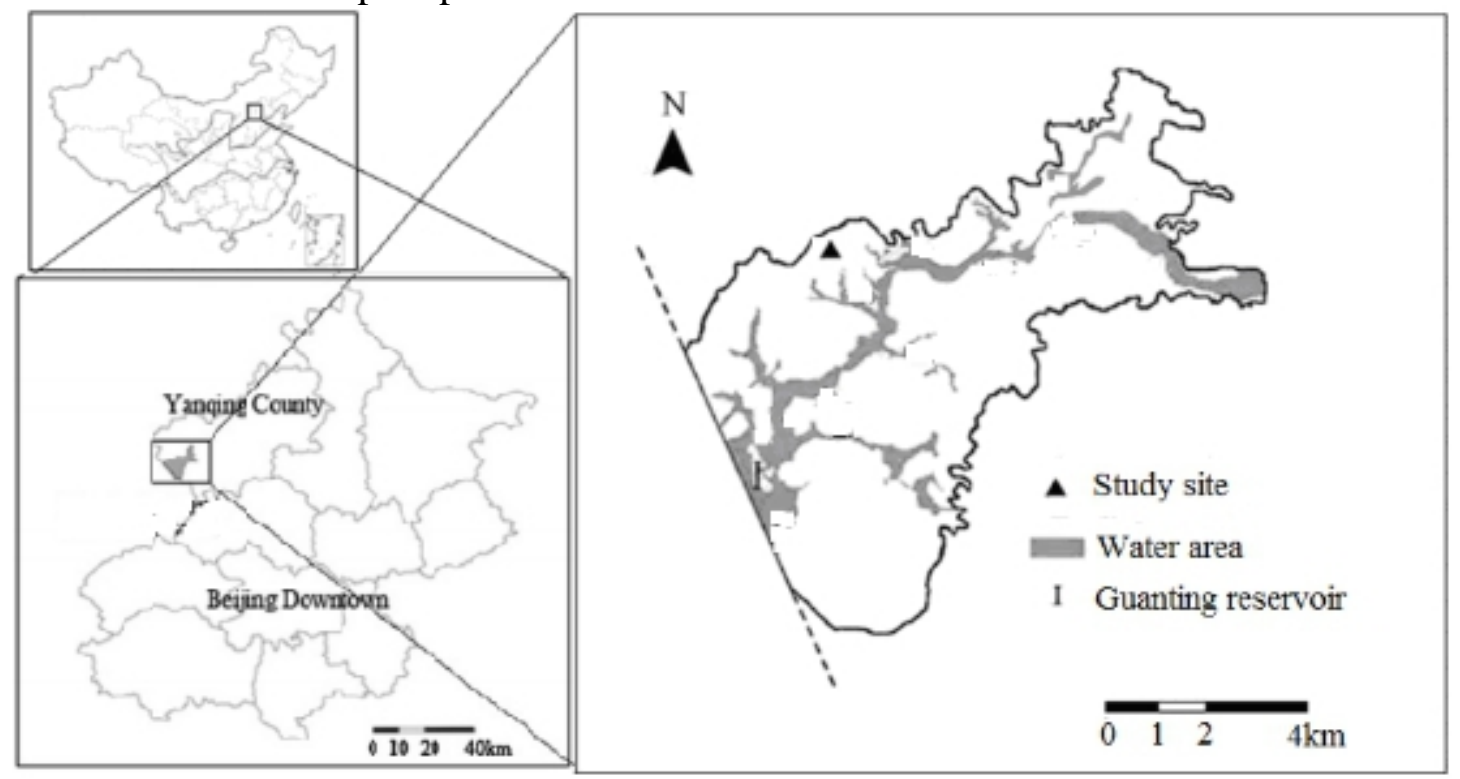

Figure 1 Location of study site

The experimental zone in SN-SSCP was newly reclaimed sandy wasteland and planted with smooth brome (Bromus inermis) and alfalfa (Medicago sativa) in June 2014 to cover the bare land and to improve soil quality. Soil at depths of $0-5 \mathrm{~cm}$ and $5-10 \mathrm{~cm}$ was sampled monthly in smooth brome and alfalfa for analysis of changes in contents of TOC, WSOC and HWEOC. TOC was measured by catalytic oxidation method, while WSOC and HWEOC were measured by method from A. Ghani [5].

\section{Results}

Monthly trend of total organic carbon content of soil Total organic carbon content of soil exhibited similar trend within one year for both depths $(0-5 \mathrm{~cm}$ and 5-10 $\mathrm{cm})$ and for both kinds of grasslands (smooth brome and alfalfa) (Fig. 1). The lowest TOC occurred in June, while the two peaks arose in May and January (Fig. 1). Additionally, taking the advantage of one-year restoration of artificial grassland, TOC had significantly improved from March 2015 to March 2016 (Fig. 1). It is suggested that the tendency of soil TOC is mainly driven by elemental factors (e.g., temperature and moisture of soil) rather than soil depth and plant species. It is also implied that both artificial grasslands of smooth brome and alfalfa can considerably increase soil TOC for topsoil $(0-10 \mathrm{~cm})$ on annual time scale.

The monthly fluctuation of TOC for topsoil was violent throughout the year with the peak twice larger than the nadir (Fig. 1), which may be the result of both phenological phase changes of plant species concerned and variation of elemental factors. Litterfall and dead roots are the dominant source of soil TOC, while microbial decomposition and leaching leakage are the main sink of soil TOC. Litterfall and root dynamics are overbearingly determined by phenology of smooth brome and alfalfa, whereas the processes of decomposition and leaching are chiefly driven by environmental conditions, such as soil temperature and soil water content.

Both smooth brome and alfalfa resumed growth in March and April of 2015, and considerable soil water was taken in by reviving grasses, so the soil became water-limited, and microbial activities increasingly restrained by dry soil conditions. In May of 2015 the drought became serious, and large amount of dead roots imported into the topsoil, meanwhile the rate of microbial decomposition was low, so the accumulated litterfall and dead roots pushed the soil TOC up to the peak of the year (Fig. 1). From June to August is the rainy season for the study area. The sufficient water and feasible temperature rendered the proliferation of soil microorganism and along with the explosion of microbial 
decomposition, the soil TOC reached the lowest point in June (Fig. 1). Afterwards, as the accumulation of dead roots and litterfall, the TOC of topsoil increased gradually month by month (Fig. 1).

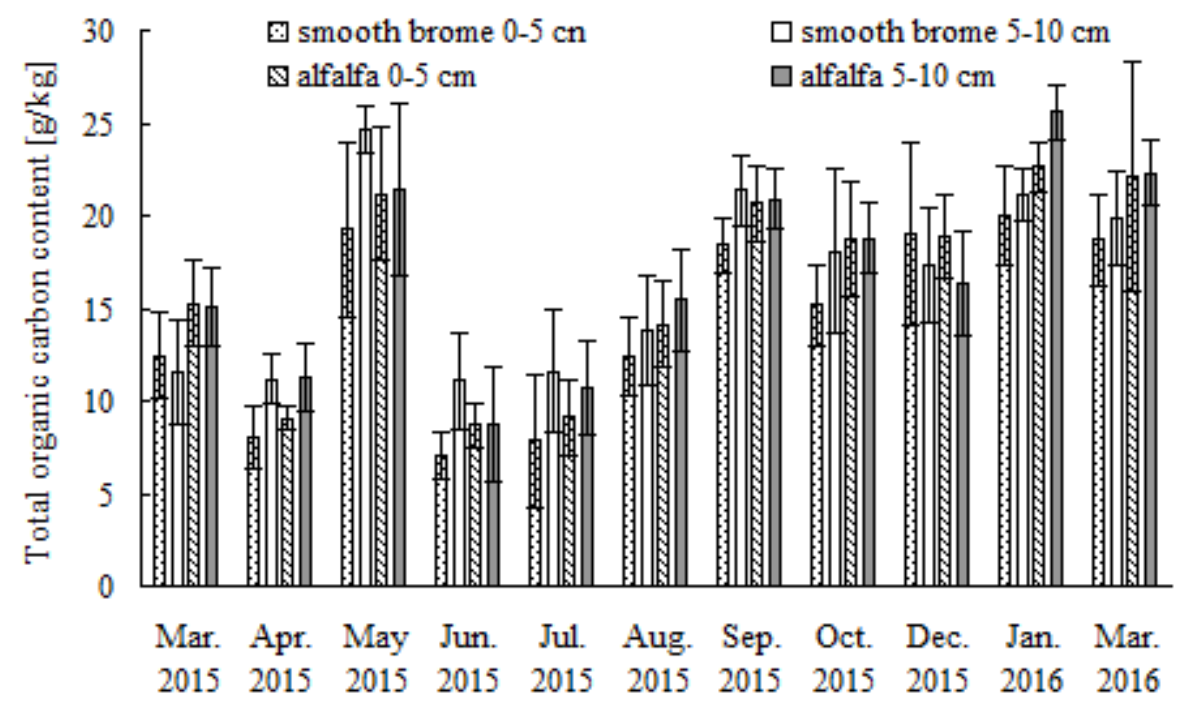

Figure 2 Monthly changes of soil total organic carbon content

Comparison of components of soil organic carbon content of topsoil On annual time scale, the TOC of topsoil in alfalfa grassland was higher than that in smooth brome grassland (Table 1). It is implied that as for TOC improvement, alfalfa grassland performed better than smooth brome grassland. Specifically, as for TOC at $0-5 \mathrm{~cm}$ soil depth, alfalfa grassland was significantly higher than smooth brome grassland, with a difference of $2.02 \mathrm{~g} / \mathrm{kg}$, while as for TOC at 5-10 $\mathrm{cm}$ soil depth, there was no obvious difference between the two kinds of grassland (Table 1).

As to water soluble organic carbon content, there was no difference at 0-5 cm soil depth between the two kinds of grassland, while at $5-10 \mathrm{~cm}$ soil depth, WSOC in alfalfa grassland was slightly higher than that in smooth brome grassland (Table 1). For both kinds of grassland, WSOC at 0-5 cm soil depth was significantly higher than that at $5-10 \mathrm{~cm}$ soil depth (Table 1). It is suggested that WSOC decreased with depth for topsoil.

Table 1 Comparison of soil organic carbon content and its components between two different artificial grasslands

\begin{tabular}{|c|c|c|}
\hline & \multicolumn{2}{|c|}{ Total organic carbon $[\mathrm{g} / \mathrm{kg}]$} \\
\hline & smooth brome & alfalfa \\
\hline $0-5 \mathrm{~cm}$ & $14.38(2.68)$ & $16.40(2.45)$ \\
\hline \multirow[t]{3}{*}{$5-10 \mathrm{~cm}$} & $16.50(2.53)$ & $16.95(2.41)$ \\
\hline & \multicolumn{2}{|c|}{ Water soluble organic carbon $[\mathrm{g} / \mathrm{kg}]$} \\
\hline & smooth brome & alfalfa \\
\hline $0-5 \mathrm{~cm}$ & $0.38(0.08)$ & $0.38(0.07)$ \\
\hline \multirow[t]{3}{*}{$5-10 \mathrm{~cm}$} & $0.27(0.04)$ & $0.29(0.05)$ \\
\hline & \multicolumn{2}{|c|}{ Hot-water extractable organic carbon [g/kg } \\
\hline & smooth brome & alfalfa \\
\hline $0-5 \mathrm{~cm}$ & $0.66(0.12)$ & $0.68(0.15)$ \\
\hline $5-10 \mathrm{~cm}$ & $0.64(0.07)$ & $0.68(0.07)$ \\
\hline
\end{tabular}

Note: the data are the average of 11 measurements sampled monthly between Mar. 2015 and Mar. 2016, with standard error in the brackets

Hot-water extractable organic carbon exhibited no significant difference between soil depths and between kinds of grassland, however, the standard error of HWEOC at 0-5 cm soil depth was obviously larger than that at $5-10 \mathrm{~cm}$ soil depth (Table 1). It is implied that with the increase of soil 
depth, as the influence of light, temperature and litterfall on HWEOC became weaker, the monthly fluctuation range of HWEOC became smaller as well.

\section{Conclusions}

Firstly, both artificial grasslands of smooth brome and alfalfa can considerably increase soil TOC for topsoil $(0-10 \mathrm{~cm})$ on annual time scale; meanwhile, the monthly fluctuation of TOC for topsoil was violent throughout the year, which may be driven by both phenology of plant species and variation of elemental factors. Moreover, on one-year scale, the TOC of topsoil in alfalfa grassland was higher than that in smooth brome grassland, while WSOC at $0-5 \mathrm{~cm}$ soil depth were significantly higher than that at 5-10 cm soil depth, and HWEOC exhibited no difference between the two soil depths. Finally, for the improving effect on all components of SOC, alfalfa grassland performed slightly better than smooth brome grassland, but the difference was not significant, and long-term monitoring is needed.

\section{Acknowledgements}

This work was financially supported by the Science and Technology Innovation Construction Special Foundation (KJCX20140301) of Beijing Academy of Agriculture and Forestry Sciences, Research and Demonstration of Technologies on Efficient Grassland Construction for the Restoration of Sandy Wasteland (KJCX20151201) and the Science Research Fund for Young Investigator (QNJJ201430).

\section{References}

[1] E. Gregorich, M.R. Carter, D.A. Angers, C.M. Monreal and B.H. Ellert: Can. J. Soil Sci. Vol. 74 (1994), p. 367-385

[2] C.A. Campbell, V.O. Biederbeck, B.G. McConkey, D. Curtin and B.P. Zentner: Soil Biol. Biochem. Vol. 31 (1999), p. 1-7

[3] A. Ghani, S.U. Sarathchandra, K.W. Perrott, D.A. Wardle, P. Singleton and M. Dexter: Proc. N.Z. GrassldAss. Vol. 58 (1996), p. 211-218

[4] M.A. Bolinder, D.A. Angers, E.G. Gregorich, and M.R. Carter: Can. J. Soil Sci. Vol. 79 (1999), p. $37-45$

[5] A. Ghani, M. Dexter and K.W. Perrott: Soil Biol. Biochem. Vol. 35 (2003), p. 1231-1243

[6] Z. Hamkalo and T. Bedemichek: Zemdirbyste-Agriculture Vol. 101 (2014), p. 125-132

[7] J. Guiguea, J. Lévêque, O. Mathieu, P. Schmitt-Kopplin, M. Lucio, D. Arrouays, C. Jolivet, S. Dequiedt, N. Chemidlin Prévost-Bouré, L. Ranjard: Soil Biol. Biochem. Vol. 84 (2015), p. 158-167 